\title{
Innovative potential of large industrial city
}

\author{
Irina Tsvetkova \\ Togliatti State University, \\ Togliatti, Russia \\ aleksandr.kozlov@mail.ru
}

\author{
Tatyana Ivanova \\ Togliatti State University, \\ Togliatti Russia \\ aleksandr.kozlov@mail.ru
}

\begin{abstract}
The article deals with social and economic aspects of reforming the city of Togliatti. Authors have analysed several development programmes involving innovative technologies, which pertain to the production diversification based on the creation of favourable infrastructure for entrepreneurship. In the context of innovational policy, the notion "innovational potential" has dual meaning. On the one hand, this notion is oriented to obtainment of quantitative evaluation of resources, which are important for innovational development. On the other hand, the potential characterizes not real processes but possibilities that could be realized as a result of overcoming a range of difficulties. The article presents survey materials of questioning Togliatti residents about the prospects for the city's further development. Analysis of the survey results has shown that more than half of respondents connect the city's development with automotive industry. Half of the survey participants think that the city's image depends on the image of cars, manufactured by the AvtoVAZ plant. Many residents associate the vision of future Togliatti with the image of an automotive capital.
\end{abstract}

Keywords-innovative potential; innovative development; city development plans; social and economic reforms; production performance; automotive industry

\section{THE CONCEPTS OF «NATIONAL INNOVATION SYSTEM» AND «INNOVATIVE CAPACITY»}

In the second half of the XX century, the speed and efficiency of economic growth was determined by the developmental level of the employee and accumulated human capital. The relationship of the economic growth speed and human development is quite complicated and is not obvious in terms of the socio-economic development of society. Governments, who followed new economic progress achievement rules, dictated by the information and innovation revolution, provided their citizens with welfare.

In Western science, the modern ideas about innovative development are connected with the study of innovation system factors. The concept of an «innovation system» was introduced by B. Lundvall in his work «Product innovation and user-producer interaction» in 1985. B. Lundvall determines the innovative system as elements and relationships. They interact in manufacturing, in a process of distributing and using new and economically useful knowledge. According to the scientist, the national system includes the elements and relationships located within the boundaries of the national state [1]. Thus, Lundvall focuses on internal characteristics. They give an idea of the system elements and the interactions between them.
C. Freeman determines the innovation system as a network of institutions in the public and private sectors, as a result of the activities and interactions of which new technologies are imported, modified and distributed. According to him, the national innovation system is formed by the interaction of the institutions; their interactions determine the innovation activity of national firms [2]. R. Nelson is close to him in his definition of the national innovation system [3].

The concept of the national innovation system is constantly being developed and deepened. The initial stage of the formation of this concept is associated with the analysis of the complex of organizational structures and relationships among them. In modern conditions it also includes a complex set of economic, political and social relationships. The concept of a national innovation system can be considered properly and generally. In the first case, the emphasis is on organizations and institutions that are directly involved in the process of scientific and technological research and implementation. Generally, this concept includes all economic, political and other social institutions, influencing the processes of education, scientific research and experimentation. In terms of the organizational structure, the national innovation system in a strict sense is universities, research institutes and the patent system. The financial system, monetary policy, competition rules, the internal organization of the private sector and many others are added to these components. At the same time, in both strict and broad sense, the national innovation system includes science as a key element [4]. The concept of the national innovation system focuses on a set of conditions that contribute to innovative development, the innovative potential formation.

The development of the «innovative potential» category is associated with a change in the rendering of innovative development, which is reflected in international documents. For example, in the latest edition of «Oslo», the guidance on conducting the innovation statistical accounting emphasizes the need to study the socio-economic infrastructure of innovation. This paper renders the innovation diffusion process, which includes both innovation development and integration into practice.

The concept of a national innovation system, where the socio-cultural aspects were reflected, was developed in the works of Russian scientists. The definition of the national innovation system, developed by Western scientists, was taken as a basis in Russian science. The analysis of approaches to the definition of this concept was implemented by Novokhatskiy [5]. The following definition of the national 
innovation system was formulated in the article of N.I. Ivanova: «... a complex of interrelated organizations (bodies) involved in the production, commercial implementation of science and technologies within national borders. At the same time, the national innovation system is a number of institutions of legal, financial and national character, provided with innovative processes and having strong national roots, traditions, political and cultural features» [6]. As I. Dezhina notes that the national character of the innovation system is mainly determined by the current national legislation and the system of informal relations [7].

On the foreground in the foreign scientists' works, concerning the study of national innovation system, there are organizational interactions among the scientific, industrial, trading firms, which contribute to the innovative development. In the publications of Russian scientists, a lot of attention is paid to social and cultural factors, influencing the innovation development.

The study of innovative capacity is one of the important directions of modern socio-economic researches related to the decision of regional development problems. In terms of management the innovative capacity is considered as a complex of statistical and economic indicators. Its characteristics allow comparing region possibilities of innovative product creating and receiving profit on its realization. A lot of techniques of region innovative capacity assessment is developed for the comparative analysis.

The concept «innovative capacity» began to be introduced for scientific use as sociological category at the end of the last century. In the Russian social sciences, the category «innovative capacity» is considered in the context of effective use of resources for achievement of innovative effect which can be expressed in technical, technological novelty indicators, usefulness, parsimony of resource usage. Nowadays the innovations are considered in the context of ecological rationality. It implies considering of safety, reliability and a decrease of negative influence on environment. During the assessment of innovations in various fields of activity the following economic criteria are taken into consideration: competitiveness, economic security of use of an innovation, profitability and possible risks. The social effect of use of an innovation is shown in the increase of indicators of satisfaction with work, in the decrease of staff turnover, improvement of social and psychological climate. Thus, the result of implementation of innovations has the complex, integrated character, making the system influence society.

\section{THE INNOVATIVE CAPACITY OF TOGLIATTI}

In terms of administrative functions, the category of innovative capacity is used in the context of creating favorable conditions for development and implementation of innovations, and implies an increase of resource usage efficiency. Innovative capacity is treated as unused, hidden opportunities of the accumulated resources which can be put in action for achievement of the economic subject goal.

In the Russian science there is a widespread point of view, that innovative capacity is assumed or already mobilized for achievement of the innovative purpose (innovative strategy realization) resources and the organizational mechanism (activity technology and organizational structure) $[8,9]$.

At an assessment of innovative development in our country the analysis of regional features is of great importance. From the point of view of A. Gerasimov, the innovative capacity of the region (field) is an ability and readiness of the region (field) to carry out effective innovative activity $[10,11]$.

Goal-oriented development of innovative capacity of a social production in modern conditions assumes the considering of content complication, structure and dynamics of resource base of innovative development; increase of a role of probabilistic factors connected with determining the ways of innovative capacity resource usage for achievement of the innovative activity goals; strengthening of functions of state regulation and innovative resource control [12].

In the context of innovative policy, the concept of innovative capacity has double meaning. On the one hand, this concept is focused on getting a quantitative assessment of resources which matter for innovative development. On the other hand, capacity does not characterize the real processes; it characterizes the opportunities which can be realized as a result of overcoming a number of difficulties.

In «The innovative development of Russian Federation till $2020 »$ it is noted that a number of important provisions of former strategy has not been implemented. The document says it has not been possible to break a number of negative tendencies, significant for innovative development. In particular, it is said that it has not been succeeded to accelerate process of integration of the Russian innovative system into world system and cardinally increase innovative activity and overall performance of the companies, and also to create the competitive environment stimulating the innovation usage. It is also told that a key problem is low demand for innovations in the Russian economy, and also its inefficient structure - an excess distortion towards purchase of the ready equipment abroad to the detriment of implementation of own new developments. In the document low interest of public sector in implement of innovations is noted.

Technology development causes essential changes of mechanisms and conditions of good production progress. Establishment of connection between natural processes and technical systems, engineering design are not the main moments but various combinations of already created and functioning elements, basic processes and the principles are.

At the same time there is a peculiar paradox which can be tracked on the basis of the sociological research result analysis. The fund of public opinion has conducted research on definition of the attitude of the population of Russian Federation regions towards innovations and how local authorities stimulate innovative development. According to the degree of knowledge of innovations, the population was divided into 4 groups: «extinguishers», «dreamers», «doers» and «leaders». It has turned out that 67 territorial subjects of the Russian Federation can be qualified to «dreamers», i.e. they have an abstract idea of innovations. However, the greatest aspiration to innovations was shown by inhabitants of 
regions where the social situation is unstable. In regions with high concentration of educational institutions (Moscow and Tomsk), the attitude towards innovations is very indifferent [13]. According to this tendency, the population of the Samara region and Togliatti, in particular, should be qualified to a group of regions highly interested in innovations.

To reduce negative tendencies in Samara region, the project of the long-term regional target program of innovative activity development for 2007-2015 has been developed, which realization is aimed at development of scientific and technological basis of Samara economy. According to the comparative analysis of territorial subjects of the Russian Federation, the level of innovative development of regions strongly depends on a geographical position, the level of knowledge in the field of innovative management, the type of regional economy (export-oriented, import-dependent, balanced), the degree of technological effectiveness of production, innovative activity and resource potential. According to complex indicators of innovative development, the Samara region is included into the list of the leading regions.

Thus, in spite of the fact that Togliatti has acquired the status of the single-industry city in the crisis period, this city is characterized by high innovative capacity, which can become a basis of progressive changes in all public life spheres and of economy diversifications.

It is thought that this paradox, which is expressed in a strong interest in innovations of the regions, having serious social and economic problems, is caused by modernization consequences. Industrial production modernization within a market economy assumes updating of technical and technological basis. However, the production modernization processes generate a lot of social contradictions [14, 15].

They are formed under the influence of a number of social factors and take part in forming social and professional groups, which are connected with innovation development and implement. First of all, innovative development of regions in modern conditions depends on political will of leaders. For this purpose, the effective system monitoring the accomplishment of innovative development programs has to be created, figuratively speaking, «force to innovate». The material incentives in innovative activity should promote to the society the general belief that if you are not an innovator, you have lost [16]. However, real social changes happen when the qualified performers of innovative initiatives take part in it. Therefore, conditions of formation and realization of the social and labor potential focused on achievement of innovative effect in various spheres of public life are of great importance. For employees (scientists, engineers, workers), participating in production of new production and technologies, there are conditions which would stimulate to innovative activity. Within the research, let us consider the innovative capacity of the industrial city as effective region resource usage conditions, which provide diversification of economy, creation and implementation of new technologies, the solution of social problems and, thereby, help to get rid of the single-industry city status.
Under conditions of Soviet society, Togliatti was an automotive capital of the USSR. Its residents were proud of the Volga Automobile (AvtoVaz) Plant — in 1970-1980, it manufactured most advanced products which were in great demand not only in Russia, but also abroad. With a highly developed social infrastructure established on the basis of large industrial enterprises, Togliatti could be rightfully considered a showcase of the socialist way of life.

In the years of reforms, social facilities were transferred under the jurisdiction of municipality, which resulted in reduced financing and deterioration in the spheres of public health service, education, sports, etc. New AvtoVAZ owners from abroad consider the plant a source of income and think in last place about the fact that its employees need decent living conditions in urban environment. In particular, the AvtoVAZ management plans to increase car production by $25 \%$, while wages and salaries are reported to grow only by $1 \%$. Amid the crisis, Togliatti, with the mass media's help, became a symbol of modern Russian monotowns (or single industry cities), and to get rid of this label has happened to be more difficult than to obtain it.

At present, there is no national concept of social and economic development in the country formulated for the various categories of settlements including small, medium, and large cities of oblast subordination. Regional development programmes do not aim to uncover cities' capacities. However, it has become a commonplace assertion that the overwhelming part of the country's available, but unused potential for development (financial, economic, demographic, intellectual, and cultural) is concentrated in the cities[17].

On 07 July 2010, the Comprehensive Programme for Social and Economic Development of Tolyatti until 2020 was approved (Resource Centre for Strategic Planning). The document consists of several parts and includes both investment and social development projects. The programme was based on the solution of two problems, being the provision of new jobs in Togliatti and diversification of the city's economy. In sight of future expansion of the labour market, a set of investment programmes (SIP) has been implemented within the framework of social and economic development in Togliatti Urban Okrug.

The Strategic Development Plan for the City of Togliatti Until 2020 involves about twenty investment projects. The implementation of these projects will obviously create employment opportunities within Togliatti.

As a result of the comprehensive programme for social and economic development, a total of 134,000 new jobs are planned to be provided in Togliatti by 2020 (of which 110,000 will be temporary ones), and the fulfilment of investment projects will provide 37,000 more positions. A huge work has been done within two years, in order to put into practice the plans, described in the strategic documents. In particular, a lot has been achieved in fighting unemployment and assuring enough work positions. As of today, the unemployment rate in Togliatti is $1.9 \%$. However, ensuring the employment of population is not the only, though pressing, problem to be solved in a monotown - there is also a range of issues related to the improvement of the level and quality of life. 
In the case of Togliatti, this is due to the characteristics of the modernization processes: the positive economic consequences of diversification expressed by the new jobs being created and the increasing profitability of enterprises, are not accompanied by affirmative changes in the citizens' lives. Particularly, this was shown by the results of an allRussian poll conducted in July 2012. Two cities in Samara Oblast, namely Samara and Togliatti, were mentioned in the list of the cities whose residents were least satisfied with the quality of their lives. The findings (VolgaInform) showed that the number of respondents satisfied with life totalled $41 \%$ in these cities, while in Russia as a whole the same index was twice as high (83\%). According to experts, the attitude towards life is influenced by such factors as sustainable working and employment conditions, income level, business conditions, effectiveness of the authorities, development of public health service, leisure opportunities, political situation in the region, and amount of attention paid by the authorities and business to the region. The worse these factors are, the less optimistic population is.

\section{MATERIALS AND METHOD}

In order to study the residents' attitude to life in a monotown, in February 2015, Sociology section's staff and students from Togliatti State University conducted a survey for the residents of Togliatti. A total of 996 respondents aged 18 to 60 years were interviewed. These age limits were chosen in order to study the opinion of people characterized by the highest employment capabilities. The questioning was conducted on the basis of proportional quota sampling among the residents with a permanent job. Sex and age served as the criteria for the allocation of quotas. The survey was conducted according to the respondents' place of residence in all city districts. This sampling model allows to correctly distribute data within the coverage error of $\pm 5 \%$ for the significance level of 0.05 on a scale of Togliatti. The data were processed with the help of SPSS 20 software.

The specificity of a monotown has been manifested in the fact that a significant part of the employable population work for the city forming enterprise. Public consciousness of the urban community is largely determined by social attitudes of the AvtoVAZ employees.

Depending on the enterprise type the respondents work for, they were represented by the following social groups: a quarter of respondents were AvtoVAZ workers; $15 \%$ of respondents worked for other joint-stock companies; a quarter of respondents worked for public (municipal) institutions; and one-third of respondents were employees of private enterprises.

\section{RESULTS AND DISCUSSION}

Depending on participation in innovative actions respondents have been divided into two groups on the basis of a respondent answer to the following question: "What is your personal participation in innovation development?». Respondents could give several answer options. The first group included innovation development participants. Among them: $2 \%$ of respondents are developer of the scientific project with innovative effect; $2 \%$ of poll participants are engaged in the invention process, rationalization; $8 \%$ of respondents are employees of a structure, which implements innovations; $3 \%$ of respondents are directors, experts of organizations, where the innovations are implemented; $2 \%$ of respondents are leaders of research groups, implementing innovations. The second group included respondents who had chosen the following answer option: «I am not involved in development and innovation implement», it included $78 \%$ of respondents.

The third part of respondents with the higher education has noted that they take part in development and innovation implement. This indicator is $8 \%$ more, than on average in the groups. Poll participants who have not graduated from higher education institutions, on the contrary, more often choose a negative answer option. Let us consider social characteristics of innovative development participants in a more detailed way.

Two thirds of the innovative development participant group consists of respondents of young and middle age (max 40 years old), senior generation is represented by $35 \%$ of respondents.

The average length of service in the organization at the latest place of work among the poll respondents is 3,1 years less than on average - 7,6 years. The indicator of the general length of service is 14,7 years and it is 3,3 years less than on average.

Among supporters of innovative strategy there are $8 \%$ less employees of AvtoVAZ than on average; however, $7 \%$ more than employees of private enterprises and $4 \%$ more than employees of state (municipal) organizations. Thus, innovative strategy supporters are not to a great extent connected with the Togliatti major employer.

Participants of innovations are distinguished by the higher educational level. Educational characteristics of the workers, being included into this group, are higher than on average; among them, there are $12 \%$ more poll participants, who have graduated from higher education institutions. Respectively, there are less participants, who have graduated from basic or secondary vocational educational institutions.

The results of interview with workers of technical professions showed that supporters of the innovative strategy of adaptation during study at a higher education institution were more often engaged in scientific researches, scientific and technological creativity. The mark of workplace equipment and a possibility of application of knowledge, gained during study at an educational institution by supporters of innovative adaptation, is 3,7 points. It is higher than on average, which is 3,4 points.

The innovative strategy supporters mark out skills of work with information technologies $15 \%$ more often than other factors helping to get a good job in the technical sphere. They also mark out knowledge of a foreign language knowledge (6\% more often). These skills are necessary for work in hitech manufacturing companies, supported by foreign investors.

The innovative adaptation supporters mark out the intellectual character of a profession among the profession 
advantages, which is $13 \%$ more often than other advantages. They also mark out an opportunity to realize abilities (9\% more often).

Participants of innovations are distinguished by higher satisfaction with working conditions. The assessment of workplace equipment and a possibility of application of knowledge gained during study at an educational institution by representatives of this group is 3,7 points. It is higher than on average, which is 3,4 points.

Satisfaction with a salary and career development of innovative adaptation supporters is 3,2 points and on average it is 2,9 points. The average wage rate is 21,0 thousand rubles and it is higher than on average among the poll respondents. If one uses a five-point scale, satisfaction with salary and career development on average is 2,9 points; it depends on the age and the length of service of respondents. The mark of the level of satisfaction with a salary and career development of poll participants with higher education is 3,2 points, and of respondents without higher education is 2,7 points. The average wage rate is 19,3 thousand rubles on average among the poll respondents. The average wage rate of respondents with higher education is 21,4 thousand rubles and the average wage rate of respondents without higher education is 17,5 thousand rubles.

Results on public awareness of the Strategic Development Plan for the City of Tolyatti Until 2020 were distributed as follows: $16 \%$ of respondents believed that they were enough informed; $39 \%$ had partially heard about it and considered their awareness insufficient; and $45 \%$ of respondents were not aware of the contents of this document. Thus, approximately a half of the working-age population were informed about the plans of Tolyatti's social and economic reforming.

A strategic priority is to provide an industrial and manufacturing special economic zone (SEZ) in Togliatti, specialized in the production of new generation high-tech automotive components for both Russian and foreign car manufacturers. Today, the city's dependence on AvtoVAZ reaches $60 \%$, while the implementation of the strategic plan until 2020 will allow reducing this dependence to $28-32 \%$. The strategic plan will also attract anchor investors and large companies to the SEZ that should be minimally related to the automotive industry. Thus, these investors will provide a new impetus for education: specialist training, creating IT and science parks will change the structure of employment and create jobs for "white-collar workers".

Assessing the prospects for change of the situation in Tolyatti in connection with the SEZ construction, the respondents expressed the following views: a third of respondents were optimistic because they believed in a change of the current situation for the better; approximately one-third of respondents believed that the situation will not change significantly; pessimism was characteristic for $4 \%$ of respondents; and $28 \%$ of respondents were undecided.

Distribution among the AvtoVAZ workers was close to the average one per sample. Survey participants, working for other joint-stock companies and public (municipal) enterprises, were inclined to an optimistic forecast by $5 \%$ more often than others were. However, the number of workers of other joint-stock enterprises, who found it difficult to answer the question, is greater by $5 \%$. The respondents, working for private enterprises, were more likely to believe that, in connection with the SEZ construction, the situation in Tolyatti will not change (by $5 \%$ ).

Hopes for positive changes in connection with the SEZ construction were more often expressed by those respondents who believed that local authorities were able to defend the interests of the territory at the highest level. On the contrary, pessimism about the SEZ is related to the fact that the respondents did not trust local authorities and believed that all decisions are made at a higher level of government.

Responding to the question about how the status of a monotown affects the image of Tolyatti, $14 \%$ of respondents chose a positive answer, considering that it allows paying attention to the city's problems on the part of regional and state authorities.

$28 \%$ of respondents rated it with more reserve and chose "Rather positive", believing that it makes one wonder about the prospects of the city. $14 \%$ of respondents believed that the status of single industry cities reduces their prestige, and $8 \%$ of respondents were of a negative opinion, believing that it forms a negative attitude towards the city. $7 \%$ of respondents thought that the status of a monotown has a neutral influence, and $29 \%$ of respondents were undecided. Thus, approximately a half of the survey respondents believed that the status of a monotown has a positive influence on its image, because it allows obtaining government support for economic development. However, the other half of respondents did not share this opinion.

When asked about the prospects of the city's development, two-thirds of respondents reported public health service as the priority sector to be developed. This answer was more common in the questionnaires, completed by medical and health workers, trade personnel, production workers, educators, and culture professionals.

More than half of the survey participants associated the city's development with the automotive industry. This answer was most often chosen by engineering professionals, qualified workers, and drivers.

Two-fifths of respondents believed that it is necessary to pay attention to education as an important resource for the development of the city. This sector was important for educators, culture professionals, service personnel, and qualified workers.

The transport sector acted as a priority for a third of respondents: it was more common in the questionnaires, completed by drivers, managers, and law enforcement officers.

A quarter of respondents recognized the importance of the cultural sector for the city's development. It was more often highlighted by educators, cultural and service workers.

One-fifth of respondents paid attention to small and medium sized business. The priority of this sector was more often recognized by entrepreneurs. 
Information technology and chemical industry were chosen by $13 \%-14 \%$ of respondents. Information technology was important for educators, culture workers, engineering professionals, and law enforcement officers.

$6 \%$ of respondents considered it necessary to develop tourism. This sector was often chosen in office workers' questionnaires.

Men marked the automotive, transport, and chemical industries and information technology more often than women did among the priorities of the city's development. Women were more likely to focus on health, culture, and education.

\section{CONCLUSION}

- Defining the priority sectors in Togliatti development by the respondents is aligned with assessing the monotown status. Those survey participants, who perceived it as a negative phenomenon, believed more often than others did that it is necessary to develop education, culture and public health service.

- Respondents, who had a positive attitude to the monotown status, more often than others highlighted the importance of information technology, entrepreneurship, and chemical industry. Interestingly, among the representatives of both groups, there was approximately the same number of those who recognized the importance of the automotive industry.

- The 2012 study addressed the issue of how the quality of cars produced by AvtoVAZ influences Toglyatti's reputation. The interconnection between Tolyatti's image and the opinion of cars, manufactured by the city-forming enterprise, is presented in the table above. About a fifth of respondents believed that the opinion of the AvtoVAZ products has a positive influence on the image of the city. Two-fifths of respondents commented more cautiously, referring to the tradition from the Soviet era, when Tolyatti used to be the capital of the domestic automotive industry. $18 \%$ of respondents believed that the image of AvtoVAZ products has a negative influence on the city's reputation.

- A quarter of the respondents had an unambiguously negative assessment, stating that a negative opinion of the cars reduces the Tolyatti's prestige. Men believed more likely than women did that connection between the opinion of AvtoVAZ products and evaluation of the city is positive, while women, in contrast, often expressed a negative point of view on this issue.

- Tolyatti is one of the largest monotowns which problems have become sharp amid the global financial crisis. Starting from the 1960 s, Tolyatti has been developing as the Soviet Union's automotive capital, and, during this period, AvtoVAZ became the city forming enterprise. On the eve of the crisis, the city economy was dependent on AvtoVAZ for more than $60 \%$.

- Upgrading technologies used and modernization of production raise a great number of contradictions. The modernization of production is associated with large social losses, which result not only in unemployment. Under the conditions of Soviet society, many social institutions in Togliatti were financed by the companies' budgets. Modernization deprives social institutions of this support, which has a negative impact on the lives of citizens. It is obvious that without successful development of industrial and technological base, no further improvement of the socio-cultural sphere of the city is possible. However, at the present stage, it is impossible to go back to the old model of Soviet-era cities, which has been repeatedly implemented in Tolyatti - the one when the city was declared an all-union construction site and yet another industrial facility was built in record time, while the development of social and cultural institutions was carried out with whatever funds remained.

\section{References}

[1] B. Lundvall, "National Systems of Innovation : Towards a Theory of Innovation and Interactive Learning, " London: Pinter Publishers,1992, pp.45-53.

[2] C. Freeman, "The Economics of Hope: Essays on Technical Change and Economic Growth", London; New York: Pinter, 1992, pp.32-34.

[3] R. Nelson, "National Innovation Systems: A Comparative Analysis, N.Y.: Oxford University Press, 1993, pp.22-29.

[4] S. Metcalfe, "The Economic Foundations of Technology Policy: Equilibrium and Evolutionary Perspectives, " Handbook of the Economics of Innovation and Technological Change, Oxford (UK)/Cambridge (US): Blackwell Publishers, 1995, pp.45-47.

[5] V. Novokhatsky, "Definition and classification of innovation systems. Innovation", vol. 9 (76), pp.175, 2004.

[6] N. Ivanova, "National innovation system, Problems of Economics", vol. 7. pp. 59-70, 2001

[7] I. Dezhina, "Technology platforms and innovation clusters: together or separately? " M.: Publishing House Of The Gaidar Institute, 2013.

[8] E. Ioda, "Resource component of innovative potential of region, Socioeconomic phenomena and processes", vol. 10 (32), pp.65-74, 2011.

[9] A. Gerasimov, "Innovative potential as a basis of economic development of regions of Russia, Business in law", vol. 6, pp.296-299, 2011.

[10] S. Forsik, "The quality of human potential as the factor of innovative development of regional economy, Problems of development of the territory", vol. 1(69), pp. 67-81, 2014.

[11] E. Egorova, N. Kulakova, "Innovative potential of a region: essence, content, evaluation methods, Bulletin of the Pskov state University. Series: Economics. Right. Management", 4, pp. 54-67, 2014.

[12] N. Nesterova, "Innovation potential: the role and place in the development of the regional economy, Socio-economic phenomena and processes", vol. 10 (44), pp.151-154, 2012.

[13] S. Polutin, A. Siedlecka, "Analysis of innovative potential of the region. Regionology", vol. 2(79), pp.110-116, 2010.

[14] R Sharapov, A. Tuzikov, A. Gilyazova, "The Role of major regional projects in the development of innovative potential of the region, Vestnik Kazanskogo tekhnologicheskogo universiteta", vol. 10, pp.340$342,2013$.

[15] A. Kalinina, "Assessment and management of innovative potential of the region", Power, vol. 3, pp.67-71, 2013.

[16] O. Chernenko, N. Chernenko, "Approaches to definition of concept and structure of innovation potential of the region", Vestnik of Tomsk state University, vol. 371,pp.149-152, 2013.

[17] N. Sobchenko, "Innovative potential of region: theoretical aspect", Kant, vol.1 (7), pp.6-7, 2013. 